\title{
The Idea of Social Life
}

\author{
LLOYDE. SANDELANDS \\ University of Michigan
}

\begin{abstract}
This paper reclaims the idea that human society is a form of life, an idea once vibrant in the work of Toennies, Durkheim, Simmel, Le Bon, Kroeber, Freud, Bion, and Follett but moribund today. Despite current disparagements, this idea remains the only and best answer to our primary experience of society as vital feeling. The main obstacle to conceiving society as a life is linguistic; the logical form of life is incommensurate with the logical form of language. However, it is possible to extend our conceptual reach by appealing to alternative symbolisms more congenial to living form such as, and especially, art.
\end{abstract}

The basic facts of human social life-that it is social and that it is alive-are easily overlooked. Yet an alien intelligence seeing human society for the first time could not but be impressed with its sheer presence-people are ever together, in the home, at work, in the cafe, theater, shopping mall, library, on the road, rails, or in the air, tied by telephone and parcel post, joined en masse by broadcast media, and connected through time and space through photograph, phonograph, novel, history, art, poem, reminiscence and imagination. Likewise, an alien intelligence could not but be impressed by the vitality of these societies. They are intricate coordinations of actions, materials, and ideas that are born, develop, mature, evolve, move, act, think, feel, disband, and die, only to be born again. Some live long, others flash for an instant. Most give an impression of life.

This paper examines the idea of social life-an idea that enjoys little prestige in social science today, but which remains one of its philosophical challenges. Although there is little room for it in a science enamored of matter, energy, and information, the idea of life won't go

\section{Received June 28, 1994}

The author thanks the editor and reviewers of Philosophy of the Social Sciences for their contributions to this work. Please address all correspondence to Lloyd Sandelands, Department of Psychology, 525 E. University Drive, University of Michigan, Ann Arbor, MI 48109-1109. 
away, and for good reasons. The paper is a set of work notes toward a conception of social life; a coming to terms. It finds in the old idea of society as organism a primary sense and understanding of human social life. The paper aims to bring this idea more squarely into focus in hopes of rooting social science more firmly in human experience.

\section{IMAGES OF LIFE}

It seems social science can hardly escape the fact of life. Many of its older texts on society (on groups, organizations, kinship systems, markets, institutions, etc), and a few of its newer ones, teem with organism. The same can be said of popular writings, which are no less telltale for being popular. No mere literary flourish, images of organism express an exuberant intuition of life that is the basis and reason for our interest in society. Such images capture the imagination, take us in.

Growing up in the shadow of natural science, under the redoubtable influence of Darwin, social science began by seeing social order as an extension or analogue of biological order. Durkheim (1893/1933) conceives the division of labor in terms adapted from Darwin's theory of speciation-particularly the idea of differentiation due to densitydependent competition. ${ }^{1}$ Others since have nursed the idea of human social life. Selznick (1956), for example, defines the social institution as "a natural product of social needs and pressures-a responsive, adaptive organism" (5). Institutional theory, for Selznick, is about natural social processes within formal bureaucracy. "Taking account of both internal and external social forces," he writes, "institutional studies emphasize the adaptive change and evolution of organization forms and practices" (12). The same concern for organism in relation to formal organization appears in Thompson (1967).

Images of organism appear also in the works of Le Bon and Freud. In crowds of certain kinds, Le Bon (1903) sees not only an organism but an organism having mental unity, a mind. And in the massive and elaborate social forms of the Prussian army and Catholic church, Freud (1922/1959) sees vestiges of humankind's archaic primate heritage as a horde animal, an image again borrowed from Darwin. By the group, Freud intends a vital entity having its own ambivalent psychology. Animal energies (which are primarily sexual in nature) compel a person to unite with others, either physically, in what Freud calls "object cathexis," or psychologically, in "identification." At the 
same time, an opposing impulse arises to reject those others who, by uniting with the person, threaten his or her autonomy. The animal's drive for self-preservation pushes people apart and clashes with the animal instinct for reproduction, which pulls them together. ${ }^{2}$ The result of this push and pull is a dynamic psychology of groups. Groups arise when forces of attraction (psychological identification) and forces of repulsion (self-preservation) play out in two vital dynamics: (1) in the emergence of a leader or object which group members incorporate into their own ego ideal, and (2) in the displacement of interpersonal antipathies (primarily envy) outside the group upon enemy outgroups, thus transforming those antipathies into mutual identification. According to Freud, the group form based upon a leader or object recapitulates an archaic primate heritage once epitomized by the (mythical?) "primal horde" and today seen in residuum in the nuclear family.

Freud's vital psychology of the group is further detailed in Bion's (1961) studies of small therapy groups. Bion defines the group as "an interplay between individual needs, group mentality, and culture" (55). "Individual needs" refers to the will of group members to satisfy conscious and rational desires; "group mentality" refers to the will of the group to act in ways that satisfy members' unconscious wishes, a will generally opposed to the avowed aims of individual members; and "group culture" refers to activity orientations and syndromes of feeling that result from conflicts between individual needs and group mentality. Three basic types of group culture vie for expression: flight/fight, pairing, and dependence. In the flight/fight culture, the group acts as if in response to a threatening enemy. In the pairing culture, the group acts as if reproduction were its primary concern, and group members form emotional bonds with one another. In the dependence culture, the group acts as if its main aim were to subordinate individual needs to the control of a dominant leader. What makes the group a group, according to Bion, is the constant interplay and elbowing for control of action and emotion elements. ${ }^{3}$

One of the earliest images of organism in sociology appears in Toennies's (1876/1957) study of the gemeinschaft. The gemeinschaft, writes Toennies, is perfect unity of individual wills. It is an organism, a unity whose elements are joined in a mutually affirming like-mindedness exclusive of individual identity and self-interest. Toennies conceives this unity to be the natural and original condition of human society, having its basis in kinship, originally of blood and family, but later in ties of geography, race, and nationality. It is signifi- 
cant of Toennies's analysis that he finds the gemeinschaft to be the only true form of society. This is in contrast to the gesellschaft, which he defines as a collection of individuals and which he diminishes as mere abstraction. "Everything real," he writes, "is organic in so far as it can be conceived only as something related to the totality of reality and defined in its nature and movements by this totality" (192). For Toennies, if only organisms are real, then society is real only insofar as it is an organism.

Distinct images of life appear also in Simmel (1971), who finds that "all sociability is but a symbol of life" (162), particularly "as it shows itself in the flow of lightly amusing play" (162). Interaction becomes a social reality when it is sensibly alive (72). For Simmel, social form is defined by two empirically inseparable elements: an interest or motive content and a mode of interaction to express that content. A good example of his concern for living dynamism appears in his description of conflict. Conflict, according to Simmel, is "designed to resolve divergent dualisms; it is a way of achieving some kind of unity, even if it be through the annihilation of one of the conflicting parties" (70). It is a mode of interaction full of life and organism:

A more comprehensive classification of the science of the relations of men should distinguish, it would appear, those relations which constitute a unit, that is, social relations in the strict sense, from those which counteract unity. It must be realized, however, that both relations can usually be found in every historically real situation. The individual does not attain the unity of his personality exclusively by an exhaustive harmonization, according to logical, objective, religious, or ethical norms, of the contents of his personality. On the contrary, contradiction and conflict not only precede this unity but are operative in it at every moment of its existence. Just so, there probably exists no social unit in which convergent and divergent currents among its members are not inseparably interwoven. An absolutely centripetal and harmonious group, a pure unification (Vereinigung), is not only empirically unreal, it could show no real life process. The society of saints which Dante sees in the Rose of Paradise may be like such a group, but it is without any change and development; whereas the holy assembly of church fathers in Raphael's Disputa shows if not actual conflict at least a considerable differentiation of moods and directions of thought, when flow all the vitality and the really organic structure of that group. (72)

Simmel adds to the image of living society in a footnote that explores the vital tension between attractive and repulsive forces of love and hate:

The highest conception indicated in respect to these contrasting pairs appears to me different: we must conceive of all these polar differen- 
tiations as of one life; we must sense the pulse of the central vitality even in that which, if seen from the standpoint of a particular ideal, ought not to be at all and is merely something negative; we must allow the total meaning of our existence to grow out of both parties.... We are everywhere enmeshed in this dualism-in the most intimate as in the most comprehensive provinces of life, personal, objective, and social. We think we have, or are, a whole or unit which is composed of two logically and objectively opposed parties, and we identify this totality of ours with one of them, while we feel the other to be something alien which does not properly belong and which denies our central and comprehensive being. Life constantly moves between these two tendencies. The one has just been described. The other lets the whole really be the whole. It makes the unity, which after all comprises both contrasts, alive in each of these contrasts and in their juncture. (emphases added, 72-3)

Finally, the image of life is also plain in Follett's concept of social organization as collective control (Follett 1937; Metcalf and Urwick 1942) and in Giddens' concept of social life as structuration (Giddens 1979). For Follett $(1937,161)$, organization is collective control; it is the natural result of actors (both individuals and groups) acting upon each other in dynamic interplay. For Giddens, who is a refreshing exception on the scene today, society comprises "forms of life" wherein social agents employ resources and rules in the recursive production and reproduction of social systems, a dynamic he calls "structuration." Here, too, society is a dynamism, a form of life, rather than a hypostatized entity. The thrust of Giddens' theoretical program is to jettison the idea of much of conventional social theory, that organization is a simple thing in the world, and to see it instead as an unfolding dynamism, a form of life.

\section{Two Examples}

Images of the life of a society or group are difficult to appreciate in the abstract, not only because life is a mystery but because it is tempting to account for a society or group in terms of the individuals who make it up. The lives of individuals are almost irresistible figures in perception, and they leave little room in mind for the life of the group. Even so, it sometimes happens that the dynamics of the group are more compelling than those of individuals.

Life is a defining intention of jazz groups and improvisational theater. Improvisation consists in ideational and actional spontaneity, fluency, and responsiveness. It is an integral organism responsively in touch with its circumstances. It is also a fragile condition disrupted 
by any loss of focus or by any failure of members to honor the group as a whole. Its minimum requirement is that group members be open enough to one another that ideas and actions can play off one another in a vital unfolding. This does not guarantee organism, but it is a sine qua non. The sure enemy of improvisation is "blocking," which arises when a member does not respond directly and honestly to the overtures of others. Whether it takes the form of defensiveness and/or withdrawal or, conversely, self-assertive stage-hogging, it is a kind of death in the life of the group. This relationship of blocking to the living dynamism of the group can be seen in this excerpt from Wierba and Allison's (1994) unpublished study of improvisational theater groups:

All of our respondents mentioned that blocking hurts improvisation. One respondent recounted a blocking example and said this about the results: "You could just feel the energy sucked out of the scene and it completely died. The scene was completely dead." Another respondent described what happens on stage when an actor blocks as returning the improvisation to the everyday. "It becomes like, unfortunately, your average conversation in real life which is that I say what I want to say, then you say what you want to say, and we don't listen to each other, you know. Like talking to your television set." (12)

A more poignant illustration of living form in a group appears in Norman MacLean's (1992) searching chronicle of the consummation by fire of all but three members of an elite crew of United States Forest Service Smokejumpers in Mann Gulch, Montana. Although there are many layers in MacLean's telling of the story, the gist of the event is as follows: On August 5, 1949, a 16-man crew of fire fighters parachuted safely to fight what appeared to be a medium-sized (60-90 acre) forest fire. Barely an hour after their arrival, all but three members of the crew were dead. Two members survived by outrunning the fire to the safety of a ridge; another member, the leader, survived by lighting an escape fire in the ashes of which he huddled as the main fire passed overhead. For the fated, unable to outrun a towering wall of flame which moved at nearly twice their speed, their last best chance of survival was lost when they failed to obey the leader's order to join him in the ashes of the escape fire.

What makes this story a compelling demonstration of the life of the group is the integrity of the group at all events and in spite of sweeping changes in its organization and logic of action. Even after its chain of authority broke down, leaving the crew without a leader, the group remained intact in its fatal flight. The men who died did so together, as a group. Their remains were discovered in a straight line 
along the path of the wildfire; and this despite the fact that their only hope of evading the fire was to take a different path up the side of the gulch to its ridge (where the fuel was thinner, the grade of the hill flatter, and the danger of the fire less). This alternate route might have occurred to more of these men had they acted as individuals. The two men who survived also did so together, as a group, by taking this alternate route. Thus, fortunate or no, crew members acted as a group. The only exception, and his position bears noting, was the leader-the one member of a group, according to Freud, likely to think and act on his or her own behalf.

Weighing against this interpretation of group life is the crew's failure to heed the orders of their leader, a lapse that has led many to conclude that every man was acting for himself. But a closer examination of this turn of events finds an even stronger affirmation of group life. The deaths of the crew did not come simply in their acting as a group, but in their acting as the wrong kind of group. In Bion's terms, its group mentality was mistaken. When the need was for a dependence culture (in which the group submits to a leader), the group was in a flight/fight culture to evade a threatening enemy. Tragically, the group's prospects for successful flight were diminished by the interval of confusion in not obeying the order that would have saved them, and, perhaps (although this is moot), by the added velocity contributed by the escape fire that would have saved them. For those who died, one imagines that there was no time in the searing final moments of fear to appreciate this dynamic of group life. For the leader who survived, there was the rest of a life to mull over his failure to lead and the group's failure to be led.

Finally, the case for the life and integrity of the Smokejumper crew also gains by contrast to accounts based upon individual psychology. One such account is proposed by Weick (1993), who explains the Mann Gulch tragedy as a crisis of meaning. In contrast to Freud, who argues that the group is made of emotional ties that are enhanced by threats to the group, Weick maintains that the group is made of shared ideas that are disproved by threats to the group. Weick thus conceives the Mann Gulch fire as a "cosmological episode" in which group bonds, and obedience to the leader, dissolved when shared meanings (which he argues were tenuous to begin with) were inadequate to meet the needs of individuals in the situation. In such a situation of confused meaning, individuals panicked and ran, every man for himself. Thus, for Weick, the tragedy of Mann Gulch was not that of a group psychology gone awry, but that of a failure of group psychol- 
ogy to hold up under the cosmological demands of desperate circumstances. However, this interpretation faces two arguments in opposition. First, it is difficult to see this situation as a crisis of meaning. The situation was comprehensible within the framework of what the fire crew was trained to do. Acting as a group, they are either to fight the fire or to flee from it to safety. The dilemma in this case, and what makes it seem to be a dissolution of the group, is that, at the same time the leader was telling the crew (somewhat paradoxically) to flee the fire by lying down inside an escape fire, the rather more impressive tower of flames rushing toward them was telling them to flee the fire by running away from it. Caught between countervailing imperatives, the group sensibly followed to its tragic end what must have seemed the more compelling of the two. Second, this interpretation is at odds with what is known about how individuals in groups respond to crisis. In what may very well be an instinctive reaction, groups under duress pull together and become more cohesive and unitary rather than less. This is reinforced by the tendency of individuals in crisis to regress to dominant modes of responding, often to the detriment of higher-level thought. Indeed, if there is ever a time when cosmology is beside the point, it is in crisis.

\section{DOUBTS AND CONCERNS}

Life is wonderful to live, but murder to say. A wide gulf separates social life as it appears to awareness and social life as we conceive and talk about it. Images are not concepts. The few concepts of life in social science attest to the difficulties of formulating them.

"The status of life in Nature," writes Whitehead $(1934,53)$, "is the standing problem of philosophy and of science." Indeed, his difficult philosophy of organism is an affidavit to this. Even biology-the science of life-fumbles with the concept and, at times, gives an impression of being ashamed of it. Typically, life is conceived abstractly as a structure or process that manifests certain functions, such as growth, development, and reproduction. However, when definition turns to empirical operations, life amounts to no more than an elaborate mechanism, a complex nexus of inanimate processes. According to the great morphologist, D'Arcy Thompson (1961): "The form ... of any portion of matter, whether it be living or dead, and the changes of form which are apparent in its movements and in its growth, may in all cases alike be described as due to the action of force. 
In short, the form of an object is a "diagram of forces" (11). For many biologists, there is no place for a dedicated concept of life or, indeed, for any vital principle. To the scientific mind interested in laying bare the causal order of life, vital principles are mystifying and obscurantist, because they deny that life can be interpreted in physical terms. This is why doctrinal vitalism is disreputable in biology. Vital principles are regarded as figures of speech, necessary in the breach, but to be dropped as soon as practicable. Writes Dawkins (1989): "Human suffering has been caused because too many of us cannot grasp that words are only tools for our use, and that the mere presence in the dictionary of a word like 'living' does not mean it necessarily has to refer to something definite in the real world" (18). A biological science must keep to what is there. As von Bertalanffy observes: "The history of biology is the refutation of vitalism" (quoted in Barlow 1991, 110). Where biology has explicated mechanical principles for vital phenomena, as it did for the entelechy proposed by Driesch, it has let go its vitalism. In biology, at least, life is not the mystery it once was (see Searle 1984).

Biology's doubts about the concept of life have not been lost upon social science, where a similar retreat from vital concepts has been underway. Once a fact, social life came to be a metaphor or figure of speech. In anthropology, this transformation is personified by Kroeber, who, in writings of 1917, describes culture as a superorganism and intimates autonomous vital properties. A generation later, in what he himself calls a recantation, he writes, "As of 1948, it seems to me both unnecessary and productive of new difficulties, if, in order to account for the phenomena of culture, one assumes any entity, substance, kind of being, or set of separate, autonomous, and wholly self-sufficient forces" (Kroeber 1952, 112). In sociology, the ascendance of structuralfunctionalism in the 1950s and 1960s altered the image of society from organism to system. When Parsons and Shils (1951) and Katz and Kahn (1966) compare the structure and function of groups to biological organisms, they are using metaphor. Their "systems" are not organisms, but clockworks. ${ }^{4}$ Today, metaphorization of organism is carried to its logical end by theorists inclined to interpretativism and to the notion that social forms are social constructions of meaning (e.g., Berger and Luckmann 1967; Morgan 1986). Organism, in this view, is only an idea for thinking about social life. It is one of many possible metaphors, or lenses, through which social life can be glimpsed. In a veritable love-in of perspectives, each metaphor is valued for its unique revelations and insights. ${ }^{5}$ 
While not objecting to the idea of life per se, other writers question its application to human society. Langer (1962), for example, argues that the conditions that permit us to speak intelligibly of certain insect societies as organisms do not obtain in the case of human societies. By comparison to the individual ant, termite, or bee whose role in the society is genetically programmed and who could not survive as an individual apart from the colony, nest, or hive, the human individual has real flexibility and choice about whether, and how, to participate in the society. The human animal, argues Langer, is distinguished in the zoological kingdom by its unique and unprecedented capacity for symbolic thinking. This capacity, which is reflected in the human awareness of self, of past, present, and future, of alternative worlds, and of personal mortality, means that the human animal inhabits a different world than the instinctively organized here-and-now world of other animals. This capacity brings with it the uniquely human need for self-expression and self-realization, which Langer calls "individuation." This is a new phylogenetic development that rises up to oppose the older instinct for social formation. The result, according to Langer, is that human society is possible only as a kind of compact among more or less free-thinking individuals. Whereas animal societies express instinct, human societies depend in significant measure upon convention and socialization. Whereas animal societies are integral organisms, human societies are organizations of free-standing individuals.

Still, the evasions of organism underscore its centrality. There are few theories of biological or social form that do not invoke an organic principle of some kind. Rarely is this principle as naked as the elan vital proposed by Bergson. Usually it comes dressed as an idea, such as goal, purpose, emergence, autogenesis, organic solidarity, adaptation, or structuration. Such ideas suggest entities that are more than Newtonian clockworks, that are alive in some way. There are important questions here. What is behind the use of vital terms? Are they a linguistic short-cut, or do they signify a deeper insight? If there is nothing to organism, what makes biological and social entities seem substantial and integral? Why doesn't the idea of organism evaporate with knowledge of mechanical details? Further, if this idea is mere metaphor, why cannot we describe the literal reality behind it?

Following Kant, Cassirer (1953) has suggested that it may be in the nature of the human mind to construe the natural world in terms of ideas of organism. The intellect, according to Cassirer, is guided by an inner idea of a determinative whole, in terms of which elements are 
conceived as parts. This is Kant's "regulative idea." In natural science, the physically given organism naturally satisfies this imaginative need, in what Cassirer describes as the remarkable suitability of the human mind for the apprehension of nature. In social science, the need for a determinative whole appears to be met by projective use of the concept of organism. The only hitch, and it is an important one, is that social organisms are not given to perception in the same way as natural organisms.

To follow the lead of some biologists and categorically deny social science the use of vital concepts makes it impossible to discover and talk about social life, should it exist. This confuses the fact that something cannot be analyzed or described verbally with the fact that it does not exist. What could be more unscientific in spirit than barring experiences that do not fit established categories and concepts? Vital principles are invoked for some reason, despite being unwelcome. Perhaps this is more than credulous innocence. Perhaps it is an awareness of a real something beyond words.

\section{TOWARD A METAPHYSICS OF SOCIAL LIFE}

We are still living in an age which I think our successors will some day look back upon with curiosity and wonder as an age characterized especially by physical realism-an age strangely blind in some, but by no means all, respects to what will then appear as outstanding spiritual reality, and concealing this behind scientific abstractions which it had taken for representations of reality and proceeded to bow down before, though they were only its own creations. (Haldane 1931, 114)

\section{From Materialism to Organism}

According to Whitehead, to understand life it is necessary to go beyond the discredited materialist metaphysics of eighteenth- and nineteenth-century science which conceives nature as spatially isolated bits of matter in motion. This metaphysics, he argued, is meaningless and discloses no ground for the coherence of life. Echoing this view, Sperry (1985) argues that biologists were wrong to disclaim the doctrine of vitalism in favor of a materialist and reductivist metaphysics. The mistake, he suggests, was in seeking properties of the whole organism in the properties of its parts. In looking for signs of life, "we biologists had been searching in the wrong places. You don't look for vital forces among atoms and molecules; you look instead among 
living things" (76). Sperry goes on to point out that you see life directly in animals as they breathe, eat, run, respond, and mate. "Among such actions and interactions, one finds plenty of evidence for vital phenomena, forces, laws, and properties that are not to be found anywhere among inanimate objects nor among the molecules of which the living are constituted" (77). A key notion in Sperry's conception of biological science is the integrity and causal primacy of the living whole in relation to its constituent chemical and mechanical processes. "Emergent entities at higher levels contain, envelop and control the properties and expression of the elementary particles" (83). The result is a metaphysics which gives precedence to life over matter.

In scientific theory, this means that the trajectories through space and time of most of the atoms on our planet are not determined primarily by atomic or subatomic laws and forces, as quantum mechanics would have it, but rather are determined by the laws and forces of chemistry, of biology, of geology, of meteorology, of psychology, even sociology, politics, and the like. The molecules of all higher living things, for example, are not moved around in our biosphere so much by molecular laws and forces as they are by the living, vital powers of the particular species in which they are embedded. Such molecules are flown through the air, galloped across the plains, propelled through the water, etc., not by molecular forces (nor by quantum mechanics) but by specific holistic vital properties possessed by the organisms. (80)

Evolution produces ever greater and more encompassing causal structures and processes. Those of life supersede those of matter. Again from Sperry:

The creative process in evolution involves control variables, forces and pressures operating at many different levels from the sub-molecular up to the ecologic, meteorologic and even astronomic ... It may have started initially at the molecular level but as the process evolves, it incorporates space-time design, pattern and form factors at higher levels that, once established, become just as real and causal as those at the molecular level. ... Human nature and these higher kinds of controls in nature don't reduce any more to physical and chemical mechanisms, but have to be reckoned with now in their own form, in their own right. Vital, mental, social and other higher forces, once evolved, become just as real as the evolved forces of molecules and atoms and must be given their due, over and above the elementary physical components. (87)

A similar argument for adopting a metaphysics of life over and against a materialist metaphysics of matter and energy was offered a generation earlier by Haldane (1931). Like Sperry, Haldane finds it impossible to describe life reductively in terms of physical and/or 
chemical structures and processes. Life, he argues, exists as a persistent coordination, the essence of which is destroyed by any attempt to parse its elements and relations. Elements of life cannot have a separate existence because each bears an imprint of every other in the coordination. Consequently, we must regard phenomena of life as an "active manifestation of the persistent whole... [this whole being] what we call the life of the organism" (14). Apart from a holistic conception of life are only endless details amongst which we grope blindly and vainly for order or sense. Also like Sperry, Haldane believes biology to be a higher plane of explanation than physics or chemistry and that reducing biological interpretations to physical interpretations degrades biology's rightful position as a supervening explanation. These are incommensurate modes of perception. To see the world biologically is to no longer see it physically, in terms of movements of matter and energy, but to see it in terms of life and its maintenance. ${ }^{6}$

A resolute concept of life requires an alternative metaphysics which identifies it as a real entity. Whitehead proposes such a metaphysics in his philosophy of organism. The very idea of "a life," he argues, implies an individuality which appropriates myriad physical processes into a functioning unity. Life is not a physical thing, but a process. It is an ongoing act of immediate self-enjoyment or selfrealization, what he calls an occasion of "experience." According to Whitehead, a life is a succession of these acts or occasions, extending from birth to the present in a single creative advance.

Whitehead's concept of life can be described only in terms of experiences that go beyond discrete physical elements and movements. The act of self-enjoyment that comprises a life is unknowable to a physical science restricted to a narrow range of objective sense perceptions. Life is revealed in the guise of vague bodily activities and wordless feelings that are more commensurate with its fluid dynamisms. Physical science misreads life because it fails to account for that vast and fundamental realm of human experience that takes place in the body: the realm of feeling.

No surprise then that an eloquent spokesperson for organism is the poet cum botanist, Goethe. "The Godhead," he writes, "is at work in the living, not in the dead; it is present in everything in the process of development and transformation, not in what has already taken shape and rigidified" (in Engard 1952, 12). "Form is something mobile, something becoming, something passing" (13). "When we study forms, the organic ones in particular, nowhere do we find perma- 
nence, repose, or termination. We find rather that everything is in ceaseless flux" (23). In a science of morphology, therefore, "we must avoid speaking in terms of what is fixed." And this because, "what has just been formed is instantly transformed, and if we would arrive, to some degree, at a vital intuition of Nature, we must strive to keep ourselves as flexible and pliable as the example she herself provides" (24).

A more fine-grained concept of life, more useful for purposes of scientific analysis, is proposed by Langer (1967). Langer finds that the integral vitality distinguishing living from nonliving is a characteristic of elements. In echo of Whitehead's philosophy of organism, Langer finds that the elements of life are not physical entities. They have not the character of things, but of acts. They are happenings within a continuous matrix of activity. As acts, they are not literally objects. Although they can be recognized as distinct and inviolable elements of an ongoing process, they fuse into one another so seamlessly that it is impossible to say where one act ends and another act begins. One act establishes the condition and grounds of another act which continues or completes the first. Succeeding acts retain the character of preceding acts, and the whole traces distinctive patterns of growth and development definitive of life. There is also a complex relation between parts and whole. Although elementary acts can be parsed for purposes of analysis, they cannot be observed independently of their participation in the dynamism of the whole. Agood example is Dewey's (1896) description of the reflex arc in behavioral psychology. Between stimuli and responses (acts psychologists take for granted) are no definitive breaks, only imperceptible transitions. Stimulus acts establish the conditions and tendencies of response acts, which, in turn, prepare the ground for further stimulus acts. A living dynamism, the reflex arc cannot be analyzed adequately as a mechanical process. Its description requires a more dynamic vocabulary.

Living forms are distinguished from nonliving forms by their patterning of act-elements. Acts comprising living forms set up a dynamic system of tensions, which Haldane (1931) describes as a "coordination of activity." Often, as one act ascends over another, it induces conditions which oppose that development, thus establishing a dialectic. Unlike the forces described by Thompson (1961) that are linked theoretically to the material form of the organism (e.g., as gravity and surface tension arise in a bacterial cell), the tensions that comprise living forms are linked theoretically to a nexus of acts. As acts collide and interact, they establish the conditions of life. Living 
forms arise in more or less obvious degrees depending upon how intensive and extensive the interplay of acts. A simple example of living form is rhythm. In rhythmic activity, one act, such as expansion of the lungs in inhalation, induces a countervailing act, such as contraction of the lungs in exhalation, which, in turn, induces a reprise of the original act, and so on in repetition. This pattern is analogous to those met earlier between stimulus and response in the reflex arc, between attraction and repulsion in Freud's group psychology, and between harmony and conflict in Simmel's concept of society. These and myriad other dynamisms among act elements are the empirical phenomena of living forms. These living forms are not only qualities of a physical system, they are phenomena unto themselves, logically and empirically distinct from physical systems. Life is to body as physiology is to anatomy. Where there is no pattern of acts, there is no living form. Tensions felt among acts are the perceptible stuff of living form.

\section{A Basis in Biology}

The argument for a metaphysics of organism in social science finds an ally in evolutionary biology. Two strands of evolutionary biology, not often found in the same weave, join to suggest that human society is a form of life. First, from sociobiology comes the argument that social behavior results from natural selection of inclusive genetic fitness. Individual behavior that is variously labeled altruistic, cooperative, or social is shown in the theory of kin selection, developed by Hamilton and later elaborated by Wilson (1975), Dawkins (1989), and others, to express selfish interests of genes. Because natural selection does not operate on individual animals, but on genes, it can produce cooperative behaviors that enhance the survival chances of a gene even while compromising those of an individual animal (as when an individual prairie dog warns others of a predator). Because kin are likely to possess the same genes, any gene that enhances the survival of kin is likely to proliferate in a population. Thus social behavior can be explained as a natural product of biological evolution.

However, social behavior is not organism. That people act cooperatively or even altruistically does not in itself constitute an organism or living form. Cooperative behavior, explicable by sociobiology, establishes only the possibility of organism. This can be seen in the social insects of the order Hymenoptera, particularly the ant. It is the entomologist Wheeler who, at the turn of the century, pronounced the 
ant colony a real organism and not just a conceptual construction or analogy. He based this claim on the many parallels between the colony and other organisms. Both are singular soma made up of individuated elements of germ plasm (ants in the colony, cells in the organism). Both take a constant form in time and space, and both are self-regulating and self-maintaining (Wheeler 1939). All of this is true, and yet the ant colony is not a living form in the sense described by Whitehead or Langer. Whereas the ant colony is a continuous matrix of activity in which actions of individual ants fuse in an integral and self-maintaining flow, it is a matrix of bare pattern and dynamism. There is little tension, rhythm, vibrancy, impetus toward resolution, or growth-in short, little vitality. The ant colony is a mechanical amalgamation of instinctive behaviors induced by chemical signals called pheromones (Holldobler and Wilson 1990). It is an impressively elaborate mechanism, but not much of a life.

Although sociobiological principles can explain social phenomena as impressive as the intercourse of eusocial insects, they cannot explain the forms of human social life. Human social behavior is not tied so neatly to genetics. Human social behavior entails a significant element of play (Huizinga 1950) which produces a new logical order-the human social form. In this social form, one finds levels and kinds of conflict, tension, dynamism, rhythm, and growth that are nowhere seen in a colony of ants or even in a troop of chimpanzees. Human social forms are organic in an unprecedented way. The place to look for social organisms is not the ant colony but the human group. Sociobiological theory cannot explain human social forms, because it reduces human social life to a story about genes and natural selection. If social organisms exist, they must be entities beyond reduction. The explanation for them must go beyond principles of natural selection and inclusive genetic fitness.

How could human society arise as a distinct logical ordering, if not by natural selection? An answer is suggested by the unique paleobiology of Tielhard de Chardin, which is the second of our two strands of evolutionary reasoning. Tielhard de Chardin offers a novel evolutionary argument for the organism of human social organization. Following Durkheim, Levy-Bruhl, and others, Tielhard de Chardin (1964) argues that a transpersonal realm of society exists as a definite evolved order that envelops and controls individual persons. The facts of this evolved order - what Durkheim calls "social facts" - are of a higher order than the facts of psychology, which are higher still than those of biology, chemistry, and physics. This transpersonal 
realm comprises a collective consciousness, a collective understanding. It is at the level of mind and idea that human society takes its organic form. "This opus humanum," writes de Chardin, which is "achieved gradually and laboriously through the growth of knowledge in the face of evil, is something other than an act of higher morality; it is a living organism" $(1964,21)$. With its development, "mankind has come to present itself less as a haphazard and extrinsic association of individuals, and increasingly as a biological entity" (155). As a result, "the relation between Society and Social Organism is no longer a matter of symbolism but must be treated in realistic terms" (155-56).

Tielhard de Chardin explains the evolution of this transpersonal organism as a result of forces released by the psychic phenomena of consciousness and reflection. "What distinguishes man's psychology," he writes, "is that he alone among the animals knows that he knows. ... What has not been sufficiently noted is that by virtue of this power of Reflection, living hominised elements are under an irresistible compulsion of drawing close to one another, of communicating, finally of uniting" (157-58). This compulsion may reflect a primitive sociability which is genetically determined and explicable by sociobiological principles. However, what happens when individual consciousnesses are brought together cannot be explained by these principles but requires new explanatory principles. In the evolution of mind, centers of consciousness do not fan out in new divergent lines, but instead fold in upon themselves (Tielhard de Chardin 1964). This process of infolding, or "inflexion," of psychic activities is the central dynamic that forms the human social organism. It is a definite movement, an ongoing closing and coiling. With it comes increasing interpenetration of elements and activities to an eventual point where so complete a unity is formed that elements meld into each other and it is impossible to say where one ends and another begins. With this movement comes also a release of psychic energies that support the autonomy of the social organism and give it life of its own.

Having introduced to paleobiology an intriguing notion of the evolution of human social organisms from inflexion of individual consciousnesses and emergence of collective consciousness, Tielhard de Chardin (1964) leaves behind a nettlesome problem. "We cannot," he writes, "distinctly view its progress because the organism encloses us, and to know a thing synthetically one has to be in control of it" (21). Yet he suggests we have intimations of this organism and that, thereby, it is not quite beyond our grasp. 
We need only to look about us at the multitude of disjointed forces neutralizing each other and losing themselves in the confusion of human society-the huge realities (broad currents of love or hatred animating peoples and classes) which represent the power of awareness but have not yet found a consciousness sufficiently vast to encompass them all. We need only recall those moments in time of war when wrested out of ourselves by the force of collective passion we have a sense of rising to a higher level of human existence. All these spiritual reserves, guessed at and faintly apprehended, what are they but the sure evidence that creation is still on the move, but that we are not yet capable of expressing all the natural grandeur of the human mission. (21-2)

For social science, the metaphysics of social life gives room to our reluctant concept of organism. By its lights, society is a living entity having determinative control over material and psychic processes of social life. Society is a definite biological order over and above the individual.

\section{Two Objections Answered}

To this metaphysics of social life two objections immediately suggest themselves - one is the charge of animism, of seeing in society a vitality that is not there; the other is the charge that human society is more than living form and thus outside or beyond a metaphysics of life. The first objection comes in the view of many writers that impressions of vitality are everywhere the makings of an overactive imagination. Piaget (1968), for example, suggests that animistic perceptions are confined mainly to early stages of cognitive development (in preverbal children aged 2-7) and later give way to different (higher?) perceptual forms. Animism, according to Piaget, is a naive and mistaken perceptual form that "results from assimilation of things into one's own activity" (27). It expresses "a confusion or a.lack of differentiation between the internal or subjective world and the physical universe" (27). With recognition of self as distinguished from other objects in the world, and with development of verbal intelligence to symbolize objects and relations, animistic beliefs are replaced by more developed ideas. Animism also is frequently noted in the mentality of so-called "primitive cultures," the adjective "primitive" conveying a similar idea of immaturity. Thus Levy-Bruhl (1926) has this to say about the "primitive" mind:

This state of mental activity in primitives ... is not a purely or almost purely intellectual or cognitive phenomenon, but a more complex one, in which what is really "representation" to us is found blended with 
other elements of an emotional or motor character, coloured and imbued by them, and therefore implying a different attitude with regard to the objects represented. (36)

And further,

The collective representations of primitives, therefore, differ very profoundly from our ideas and concepts, nor are they their equivalent either. On the one hand ... they have not their logical character. On the other hand, not being genuine representations, in the strict sense of the term, they express, or rather imply, not only that the primitive actually has an image of the object in his mind, and thinks it real, but also that he has some hope or fear connected with it, that some definite influence emanates from it, or is exercised upon it. This influence is a virtue, an occult power which varies with objects and circumstances, but is always real to the primitive and forms an integral part of his representation. (37-8)

The animistic thinking of primitive peoples is viewed the same way as that of children-as naive, immature, unformed, unsophisticated, and wrong.

To say animate perception is unsophisticated is not to say it is unrealistic. A closer look belies the disparaging view taken of it and shows that view to be scientistic, even culturally elitist. Recent research in psychology finds substantial animism in adult perceptions, enough perhaps to question if it is a passing feature of immaturity. Sheehan, Papalia-Finlay and Hooper (1980) present data for 90 subjects, aged 6 to $65+$ years, showing a high frequency of animate responses in all age groups. These responses are unrelated to logical classification ability or to analytic cognitive style. Seitz and Beilin (1987) examine levels of response to physiognomically suggestive visual metaphor in photographs in 70 children ranging from preschool to college age and ranging in IQ from medium to high. Young children show significant levels of physiognomic responding; older and high-IQ children show even higher levels of response. In opposition to Piaget, there are good reasons to think animate perception is an innate capacity of practical intelligence that develops with use and that is not superseded by more refined perceptions. This is suggested particularly by neurological studies that find brain processes specifically devoted to perceptions of living form. Nielson (1962, 81-2) reports three cases of visual agnosia in which patients suffering lesions to the left occipital lobe of the brain cannot recognize and revisualize animate beings but can recognize and revisualize inanimate objects without impairment. Contrariwise, there are reported cases of visual agnosia in which perceptions of inanimate objects are 
impaired and perceptions of animate beings are intact. It seems the brain makes a distinction between living and nonliving beings that social scientists cannot. Finally, and going beyond evidence of its neurological basis, interest in animate perception is warranted for the evolutionary advantage it confers to an animal having predators. Quicker to see its nemeses, this animal lives to procreate another day.

The most important defense of animate perception, however, is that, in key respects, it is more realistic than the more "developed" mode of perception that Piaget identifies with adult intelligence. Whitehead (1934) criticizes the latter mode of perception, which he identifies with positive science, for ignoring basic facts of the natural world such as that it is coherent and that it is alive. By fixing narrowly on sense perception (especially vision), modern science ignores wide realms of feeling that are also part of human experience. The result is a superficial and unrealistic view of the world composed of objects, an error of conception he calls the "fallacy of misplaced concreteness." Brown (1959) goes further to argue that scientific perception is not only mistakenly concrete but reflects an unhealthy anal-sadistic character structure. Scientific perception, according to Brown, is an unconscious flight from the living body that arises from a basic anxiety about death. Such perception, he argues, is a kind of "death-in-life" that denies the proportions of life in the world.

Although acknowledged as a problem in philosophy and psychoanalysis, the flight from animate perception is largely unrecognized as a problem in social science. According to Brown (1959), "Contemporary social theory (again we must honor Veblen as an exception) has been completely taken in by the inhuman abstractions of the path of sublimation, and has no contact with concrete human beings, with their concrete bodies, their concrete though repressed desires, and their concrete neuroses" (318). The explanation for this is perhaps the familiar one, namely, that social science has moved too quickly to emulate big brother physical science. Instead of keeping strictly to phenomena of social life, vague and inchoate though they may be, it has confined itself to objects it can find, rushed into formalization, and turned its back on the problem of knowledge.

A second and related objection to the metaphysics of social life comes in the claim that human society is not an order of nature but something else again (see, e.g., Haldane 1931). From the premise that human consciousness is beyond life-that its aspects of valuation and intention constitute a logical order beyond the biological—it could be argued that insofar as human society exhibits consciousness (such as 
by having its own purposes, values, plans, memory, regrets, and the like), then explanations based on a biological concept of life cannot be applied.

This seemingly powerful objection rests on a bifurcation of mind and body (and, by implication, a bifurcation of psychology and biology) that need not be honored. Consciousness need not be conceived apart from the body, but can be thought of as an aspect or phase of body process. Consciousness is a biological phenomenon, a phenomenon of life that arises under special circumstances of biological evolution. Thus, in considering human society as living form, analysis need not be confined to a cribbed concept of life that excludes consciousness and mind. As noted above in regard to Tielhard de Chardin's paleobiology, the mental aspects of human society may make it vital in ways that other animal societies are not. And even Haldane (1931), who might be first to voice this objection, observes that the human animal is alive in the double sense that its unity of activity is expressed both over time (in virtue of its memory and consciousness) and over space (in virtue of its physiology). What is new in human experience is a greatly enlarged vitality that goes beyond physiology into consciousness. Therefore, even if human society is substantially minded (see Sandelands and Stablein 1987), it is not on that account beyond living form.

\section{TOWARD A SYMBOLISM OF SOCIAL LIFE}

A basic problem of social science is to symbolize social life so we can think and talk about it. This is the problem of conception. Our rich sense of the life of society is disappointed by impoverished concepts. As suggested above, our convictions about society rest on inchoate intuitions, or feelings. Society has for us a physiognomy but no conceptual identity. A science of society requires symbols that have both experiential and conceptual content, symbols coordinate with feelings of society that can be integrated in a scheme of thought.

\section{Language and the Cap of Invisibility}

We have trouble symbolizing social life because we do not often enough go beyond the bounds of natural language. Human society cannot be described by language because it does not stand still long enough to be looked at and named; it is too vital, too diffuse. Language 
is a discursive symbolism having two logical properties: (1) it isolates meanings into more or less individuated units, and (2) it lays these meanings out as a string of pearls, one after another in time. These logical properties are key to its strengths and weaknesses as a symbolism. The strengths of language stem from its isolation of meanings into nameable units, such as words or phrases-that is, its objectpredicate structure. Through naming, whole realms of experience are consolidated in simple denominations that can be compared. This not only makes for efficient signification, it makes the symbolism itself a kind of memory. As etymology shows, language comprises a history of understanding. Naming also makes possible discovery of hidden or latent meanings by means of metaphor. In judging similarities and differences between concepts, new concepts can be invented adding depth and nuance to thought. Finally, naming makes for combinatorial flexibility. By segregating meanings into individual units and arraying them in a sequence, meanings can be substituted and combined in innumerable ways, limited only by conventions of syntax (and even then sometimes in violation of these conventions).

Because of its power and flexibility, language is the dominant symbolism of sentient life. Wherever exercised, it overwhelms more subtle modes of symbolism. As Langer (1967) notes:

Discursive thinking, once started, runs on in its own loosely syllogistic pattern from one proposition to another, actually or only potentially worded, but with prepared forms of conception always at hand. Where it seizes on any material-sensations, memories, fantasies, reflectionsit puts its seal of fixity, categorical divisions, oppositions, exclusions, on every emerging idea, and automatically makes entities out of any elements that will take the stamp of denotative words. (155)

This all-over-the-road imperiousness of language comes at a price, and that price is an inability to symbolize phenomena that cannot be decomposed into objects and predicates. Language compiles experience in a way that makes only certain conceptions possible. Experiences that fit the logical form of language are conceivable, those that do not are distorted or left to remain ineffable. This second category includes all experiences of interaction, vitality, and feeling. By subjecting such phenomena to their object-predicate structure, a structure which makes substances even of nonsubstances, language produces a "cap of invisibility" (Langer 1967), which obscures processes and dynamisms.

Arnheim (1966) discusses the problem of using discursive language to conceptualize the idea of interaction, using the principle of 
yin and yang in Taoist Chinese philosophy as an illustration. Taoist cosmology conceives nature as unceasing change in which existence moves in an eternal "Return of the Same" (225). Nature is a "stationary flux" (225) constituted by continuous and fluid interaction of the female principle of yin (representing darkness, cold, moisture) and the male principle of yang (representing light, warmth, dryness). By interacting, these opposites produce the myriad forms and dynamisms of nature. How, Arnheim asks, can we conceptualize this interaction? In answer, he considers four concepts of interaction that can be described discursively: (1) "mutual bombardment," in which stable entities do things to each other; (2) "circularity," in which one entity influences a second, which then turns around to influence the first in a feedback loop; (3) "network," in which elements are interrelated in a causal system; and (4) "hierarchic differentiation," in which parts define the whole and, in turn, are defined by the whole. In reflecting on these four models, Amheim concludes that not one does justice to interaction.

They all fail, not because of individual defects but because the task of describing interaction discursively is insoluble in principle. Conceptual theory can predict the outcome of interaction but it cannot adequately describe the process itself since by its very nature it can account only for linear connections among entities. All language is subject to the same limitation. (231)

To conceive the interaction of yin and yang, Arnheim argues, there is no choice but to approach the problem perceptually, as, for example, through the well-known visual symbol, the T'ai chi tu (see Figure 1). "Perception," writes Arnheim, "accomplishes the feat the intellect fails to describe; for perception is interaction" (232). Understanding interaction involves perceiving the behavior of configurations of visual forces which are spontaneously "interpreted" as images of the behavior of forces in the interaction itself. Arnheim goes on to analyze the visual forces presented in the T'ai chi tu to show how it symbolizes the interaction so fundamental in Taoist cosmology.

What is true of interaction is true even more of complex dynamic forms, such as societies. Society, likewise, cannot be put into words. The object-predicate form of language invites conceptions of society as a system of persons and relations, not as an integral living form rooted in actions (Sandelands and St. Clair 1993). As a result, the felt experience of society goes undescribed. One can see that a society is made of persons but cannot see the society itself. 


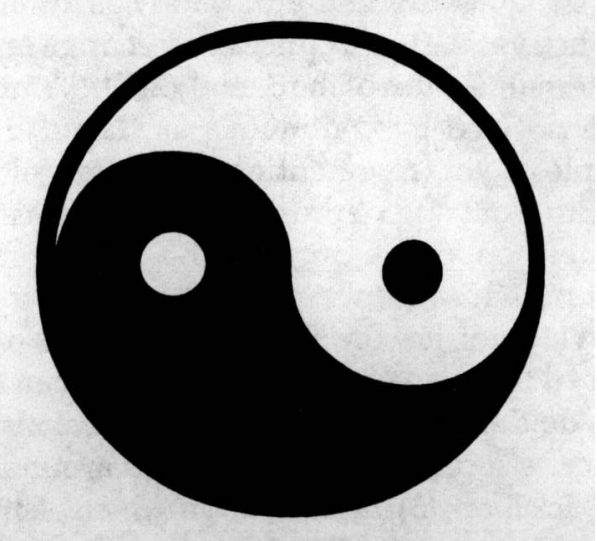

Figure 1: The T'ai chi tu

The dimensions of this problem can be seen in theories of society that must make do with words. Most theories of organization are in the tradition of Parsonian structural-functionalism (Dow 1988). This tradition explains organization by dynamics that fit or adapt organizations to environments. It is said either that organizations "adapt" to their environments or that their environments "select" them out if they are unadapted. As the author and Robert Drazin have elsewhere argued (Sandelands and Drazin 1989), a problem with these perspectives is that they describe a world that does not bear close scrutiny. They speak of organizing processes that cannot be verified. When we look behind the words, we find nothing so concrete or definite as the words suggest. If it is asked how environments determine organization, the answer usually given is that they "select" or "choose" one that is appropriate. However, to say that organization is selected or chosen only incorporates the fact to be explained in the verb used to do the explaining. The verbs to select and to choose do not refer to definite activities, but rather to the consequences of unspecified activities. What appears to be a process only seems to explain organization.

Structural-functional theories of organization are undermined by words that do not name experiences. They attribute a misplaced concreteness to the paradigmatic words organization and environment, neither of which abstracts an experience; organization is flatly asserted, environment is defined negatively by substraction of the organization from everything else. This explains why structural- 
functional theories rely upon vacuous verbs such as select or adapt to do their bidding; as organization and environment are unestablished, they can be related only by imaginary processes that operate (conveniently) behind the scenes.

There are problems no less in Giddens' theory of social organization as structuration, which is posed as a radical alternative to structural-functionalism (Giddens 1979). In this case, however, the problem is not mislaid concreteness, but interaction. Discursive language fails Giddens the same way it fails Arnheim. Giddens' main insight is that human knowledge of society and its workings must be incorporated in any theory of that society. Humankind is unique in the animal kingdom in the extent of its self-knowledge. This knowledge is an element in the production and reproduction of society in a process Giddens calls "structuration." Structuration theory finds social life to be recursive, by which Giddens means that its essential feature is interaction between the human individual's capacity to act according to his or her will (human agency) and the practices and resources that constitute the social system (its structural properties). The structural properties of social systems thus are both medium and outcome of practices that constitute those systems. Giddens calls this the "duality of structure." The social system is the structured totality, the social form. It is a continuously reproduced order of spatially and temporally situated events. This concept of social system is a picture of life, a ceaseless flux, an ongoing creative development. It is Whitehead's "organism," Langer's "living form."

The main problem for structuration theory is that discursive language cannot convey the process. Language symbolizes propositions, but the basic ideas of structuration theory are not propositional. The paradigm concepts of structure, system, and structuration are incommensurate with the object-predicate form of language. Structuration is interaction. As discussed in the example from Arnheim above, referring to structuration, as Giddens does, as "mutual dependence" (in Arnheim's phrase, "mutual bombardment") or "recursiveness" (in Arnheim's phrase, "circularity") only highlights the problem of symbolizing it discursively. Mutual dependence and recursiveness suggest that structure and agency exist separately, independently of each other and of the whole, and yet this is not what Giddens intends. For Giddens, agency and structure can be separated analytically, but not in fact. The concept of structure likewise poses a problem of conception. Giddens defines structure as dual; at once a medium of practice and an outcome of practice. Structure is a strange amalgam of means 
and end; not quite a process and not quite a thing, but somehow both and neither. It both exists and does not exist. "Structures," writes Giddens (1979), "exist paradigmatically, as an absent set of differences, temporally present in their instantiation, in the constituting moments of social systems" (64). Such a structure cannot be bent to the object-predicate structure of discursive language. Finally, the concept of system enjoys all the mystery of any other concept of living form (see above). Giddens defines system as a reproduced order of spatially and temporally situated events. But this definition is so vague that it hard to tell what, if anything, answers to it. The word system functions the same way as other words for society, as a placeholder for an unconceptualized intuition of form. To be sure, Giddens' definition of system is new. Yet it seems not to live up to its author's own inner idea of system: an idea of society as a life.

Giddens seems au are of these difficulties when he acknowledges that structuration is not a substantive theory of the constitution of society, but rather a statement about ontological first-principles. It is a statement about what a theory of society should be like and what it should not be like (see Cohen 1989). Structuration theory is explicitly critical of structural-functional social theory for, among other things, reifying structure and system, not recognizing the reflexiveness of social knowledge, making a paradox of the relationship between human agency and social structure, and not recognizing the temporality of social forms. Against the backdrop of structuration theory, one can better see failings of structural-functional theory as a conception of society. Nevertheless, structuration theory offers nothing in place of the insubstantiality of structural-functionalism. Rooted no less in language, it is subject to the same limitations. It offers, instead, a kind of ontological correctness. It is clear about the many ways language is unkind to our experiences of society and social life. But, like other forms of correctness, it is fuzzy about how language should be used. For no gain in conceptual power, it promises only fewer violations of social life as we know it and more sanctimoniousness about the violations that occur. In these respects, structuration theory is an object lesson about the limits of discursive language for a science of social forms.

\section{Presentational Symbolism and the Shock of Recognition}

Social science requires a symbolism capable of representing social life with objects or forms that can be reflected upon. It requires 
symbols that can be assimilated into ongoing thought about social life, and it must avoid symbols, such as those of language, that do not demark experiences. These last are rocks that impede the flow of scientific thinking, slowing it down and mixing it up in eddies of nonsense.

An invaluable clue about symbols for social life comes from the animistic mentality of children and members of primitive cultures. Their world is sensibly alive; its objects are linked in a coherent drama of forces, oppositions, tensions, and dynamics. Their ideas of things are built upon a logic of life, instead of a logic of discursive language. A case in point is the primitive's idea of clan as a totem. The totem is almost invariably a living being, vegetable or animal, that expresses by its vitality a sense of the clan as a living body and the perceiver's part as a member. As Levy-Bruhl (1931) points out, for the primitive the idea of being a "member" is not a metaphor but a literal expression of a sensible fact.

Langer (1951) called the symbols of the primitive and the child "presentational symbols," in contrast to discursive symbols, and in respect to their logical properties of wholeness, simultaneity, and interaction. Others refer to these symbols using terms such as gestalt, bildung, expressive form, and significant form. Presentational symbols are perhaps best known to us in works of art. Art presents images of felt life. The primary function of art, as Langer (1962) points out,

is to objectify feeling so that we can contemplate and understand it. It is the formulation of so-called "inward experience," the "inner life," that is impossible to achieve by discursive thought because its forms are incommensurable with the forms of language and all its derivatives (e.g., mathematics, symbolic logic). Art objectifies the sentience and desire, self-consciousness and world-consciousness, emotions and moods, that are generally regarded as irrational because words cannot give us clear ideas of them... . Art presents the life of feeling for our contemplation. It is the articulation of the morphology of feeling through wordless abstraction. (90)

The significance of art, in this view, goes beyond its functioning as an expression of inner life. It is also, and fundamentally, a mode of discovery and conception. "The artist," writes Cassirer (1953), "is just as much a discoverer of the forms of nature as the scientist is a discoverer of facts or natural laws" (184). As a symbolism, art is a way of seeing, a means of meeting the world, and a means of constituting its meaning. Through art, as opposed to discursive symbolism, it is possible to understand realms of sentient life associated with feeling that would otherwise be incomprehensible. 
The special power of art as a symbolism is its representation of vital forms that cannot be rendered discursively: wholeness, simultaneity, interaction, dynamism. The artist aims to transmit feeling. As feeling is a culmination of vital process (a phase of vital activity), any symbol of feeling must resemble the vital process from which the feeling issues. All forms symbolic of feeling must, therefore, appear to be living. The art object, notes Langer (1967), objectifies a feeling by presenting a semblance of a living form in terms of which the beholder can conceive it. This semblance of living form is experienced by the beholder as a "shock of recognition." It is an awareness that the artwork is true to life in its rendering of feeling.

The semblance of living form in art is produced by a logical structure that mirrors life. The elements of art, like those of life, are not things but acts. They are virtual constituents that are likewise "indivisible and inalienable from the whole" (Langer 1967, 200). Furthermore, the dynamic structure of these elements is cognate to the dynamic structure of acts in living organisms. Of these elements, Langer writes:

All artistic elements whatever-all distinguishable aspects of the created work-have formal properties which, in nature, characterize acts. Inviolability, fuseability and the revivable retention of past phases in succeeding ones are some of those properties. Another... is the relationship of elements to the whole, which is very complex, so that it is ordinarily not possible to designate it as a single relation. Every element seems to emanate from the context in which it exists. (202)

Furthermore, and although produced by artistic illusion, the unity and substantiality of the artwork rest upon many of the same principles as the unity and substantiality of living forms. Unity stems primarily from interdependence of elements, and particularly as secured by tensive relations. Substantiality is produced by the interaction of illusions, often by a primary illusion set against less developed secondary illusions. The result is a work of protean character, a work of vitality, of indefinite possibilities that remain to be worked out. The artwork becomes a virtual life, "a progressive realization of potential acts" in which "every realized act changes the pattern and range of what is possible," thus making the living body "an ever-new constellation of possibilities" (206).

Presentational symbols, such as works of art, achieve their effects through the modes of perception to which they appeal. For example, the great power of visual symbols arises in the symbolizing capacity of the human visual system. Visual perception is visual thinking 
(Arnheim 1969). Unlike the discursive symbolism of language, which of necessity is considered piecemeal, one object and relation at a time, visual images are taken in all at once. The perceiver can see any organic pattern of acts and intuit its meaning directly, without linguistic mediation. Visual images make ideal symbols of life. Arnheim (1966) calls this the capacity for "spontaneous perception of symbolic meaning." It will only be by turning to presentational symbolisms, such as visual images, that social science will succeed in establishing an empirically based idea of the form of life we call society.

\section{SUMMARY AND CONCLUSION}

This paper has examined the idea of organism in social science. It has found that, despite being indispensable in social science writing, organism remains largely unconceptualized. For this reason, it has been a reluctant concept, both in biology, which first saw the need for it, and in sociology, which has seen the need for it since. It is an idea that lurks at the fringes of social science, not quite legitimate, but too close to naive understanding and too useful to give up completely.

Further, we have seen that, to be taken seriously, the idea of social organism requires a new metaphysic, a metaphysic of life that contrasts with the limiting materialist metaphysic of eighteenth- and nineteenth-century physical science and that suggests new avenues of investigation and inquiry. This is a familiar point made long ago, and better, by Whitehead, but not for that reason less valuable to repeat. An outline of this metaphysic, which borrows from Whitehead, Dewey, Langer, and Tielhard de Chardin, is offered in suggestion of the work left to be done in bringing organism into the realm of scientific study.

Last, we have considered the problem of symbolizing social life. Discursive symbolisms, such as language, are found to be logically incommensurate with organism and thus incapable of representing it adequately. Their object-predicate structure places a "cap of invisibility" over social life, putting it beyond the pale of discursive report. Presentational symbolisms, on the other hand, such as those which appear in the mentality of children and in primitive cultures, and which are developed acutely by artists, are found to be ideally suited to organism. As their logical properties of wholeness, simultaneity, and interaction are the logical properties of life, they can represent organism in the mind's eye and so produce the "shock of recognition" 
that validates our experiences of social life. These symbolisms are the stuff of which an idea of society as organism can be made. It is only by appeal to these latter symbolisms that social life can be an object of reflective awareness and systematic scientific study.

Returning to the images of society with which we started-Freud, Bion, Le Bon, Toennies, Simmel, and MacLean-we can better appreciate the glimpse of organism they afford. In them, we see act and feeling elements in patterns of tension and dynamism. In them, we find patterns of growth and development characteristic of organism. Each condition of the group bears the stamp of conditions before it. Early events and dynamics foreshadow later events and dynamics, producing a unique history and personality. The group appears as nothing so much as an adaptive and growing organism. It is also possible to see in these portraits the peculiar relation of parts to whole that distinguishes living from nonliving forms. Whereas their partswhich are acts, not things-can be parsed for purposes of analysis and exposition, they cannot be observed independently of their participation in the dynamism of the whole. Although it remains for future work to develop symbols of social life and to integrate those symbols in a conception of social life, this paper is an initial effort of due diligence to gauge the soundness of making the necessary investment of time and energy. Surely the prospects are promising enough to go a little farther.

There is, finally, an irony in the idea of organism applied to human social life. In an odd turnabout upon the concreteness of natural life as compared to social life (i.e., plants, animals, and even microbes can be seen in ways that societies cannot), organism may be easier to discern in the latter than in the former. Whereas in natural life, perceptions of organism compete against more compelling perceptions of physical form, there is no such competition in social life. Because social science does not enjoy the same advantages of observation, it may be easier to appreciate organism in it. Social science may teach biological science something about the nature of life. A final aim of this paper, therefore, is to begin to bring faint and guessed-at apprehensions of social life into the light of reflective awareness where they can become proper subjects of scientific study and debate.

\section{NOTES}

1. This parallel is not absolute, as Durkheim is careful to point out. Whereas in the theory of speciation, contesting species fight to the death, in the division of labor, 
contesting parties fight only to reach a new reconciliation, wherein an original mutuality and solidarity is transformed and preserved in a new form (original mechanical solidarity is transformed to a new organic solidarity).

2. Freud illustrates this dialectical tension with the help of Schopenhauer's famous simile of the freezing porcupines.

A company of porcupines crowded themselves very close together one cold winter's day so as to profit by one another's warmth and so save themselves from being frozen to death. But soon they felt one another's quills, which induced them to separate again. And now, when the need for warmth brought them nearer together again, the second evil arose once more. So that they were driven backwards and forwards from one trouble to the other, until they had discovered a mean distance at which they could most tolerably exist. (quoted in Freud 1922/1959, 41)

3. The vital images detailed in the work of Freud and Bion were later elaborated by Stock, Thelen, Lieberman, Hare and others of the Human Dynamics Laboratory at the University of Chicago. As summarized by Stock and Thelen (1958), this work rests upon an image of the human group as a life unto itself-as an adaptive process. "The word 'group,' " they write, "stands for some organizing principle that enables us to see the behaviors of individuals, not as random, separate events, nor yet as simple stimulusresponses connections, but rather as having a place within a manifold of behaviors that began in the past and can be projected into the future" (9). On the one hand, the group is a definite phenomenon; $a$ vital flow, $a$ manifold of behaviors with a past, present, and future. On the other hand, the group is not a simple "thing" to be seen or touched, but a word for some organizing principle. The group is not an object, but a life.

4. Today, the literal concept of organism survives only at the controversial margins of social science, in the fields of sociobiology and complex adaptive systems. Sociobiology, first outlined by Wilson in $\mathbf{1 9 7 5}$ and since fought about more for its moral implications than for its substance, seeks to establish the genetic basis and evolution of animal society, including human society. It argues that certain social behaviors and forms evolve by natural selection (i.e., as genomic adaptations to circumstances). The theory of complex adaptive systems propounded by Holland (1992) and others likewise construes social systems, such as economies and social organizations, as adaptive organisms which reproduce and adapt by means of genetic algorithms that resemble those described in molecular genetics. Sociobiology and complex adaptive systems theory thus recall some of the insights with which social science began at the turn of the century.

5. This postmodern strain of theory thus radically opposes the earliest ideas of social theory which insisted that concepts of social form be rooted in literal concepts of organism. It would be fascinating to know how the early theorists would greet the ideas of their postmodernist offspring. One imagines they might recoil in horror, believing that social theory can advance only if it again takes literally the idea of organism and returns it to good standing from the netherworld of literary trope. From their vantage point, there is great danger in the idea that social scientists should not think literally.

6. Haldane adds an intriguing suggestion that biological interpretation is prior to physical and/or chemical interpretations. He argues that persistent coordinations, which are the subject of biology, are the first facts of nature and come before those taken for granted by physics or chemistry. It is a mistake, he suggests, to inquire of the physical or chemical origins of life. There are no origins of life; it has always existed. There never 
was, and could never be, a movement from nonlife to life. The question arises only as a misconception stemming from the narrow metaphysics of Newtonian physics that conceives a world of independent objects and relations. Haldane concludes: "However low down we may go in the scale of life, and however far back we may trace the development of life, it is still life that we find" (38).

7. This point is suggested by the development of the science of morphology, particularly as it appears in the pioneering work of Goethe. As Engard (1952) points out in his introduction to his collection of Goethe's botanical writings, Goethe's concept of morphology as an ever-moving process of becoming could arise only with his rejection of the Linnean analytical typology of species which was based upon observations of the fixed and unchanging characteristics of visible life forms.

\section{REFERENCES}

Arnheim, R. 1966. Toward a psychology of art. Berkeley, CA: University of California.

1969. Visual thinking. Berkeley, CA: University of California.

Barlow, C. 1991. From Gaia to selfish genes. Boston: MIT Press.

Berger, P., and T. Luckmann. 1967. The social construction of reality. Garden City, NY: Anchor.

Bion, W. R. 1961. Experiences in groups. New York: Basic Books.

Brown, N. O. 1959. Life against death. Middletown, CT: Wesleyan.

Campbell-Fisher, I. G. 1951. Intrinsic expressiveness. Journal of General Psychology 45:3-24.

Cassirer, E. 1953. Essay on man. Garden City, NY: Anchor.

Cohen, I. J. 1989. Structuration theory. New York: St. Martin's.

Dawkins, R. 1989. The selfish gene. New York: Oxford.

Dewey, J. 1896. The reflex arc concept in psychology. Psychological Review 3:1-15.

Dow, G. K. 1988. Configurational and coactivational views of organization structure. Academy of Management Review 13/1:53-64.

Durkheim, E. 1893/1933. The division of labor in society. Translated by G. Simpson. New York: Macmillan.

Engard, C. J. 1952. Introduction to Goethe's botanical writings. Translated by B. Meuller. Honolulu: University of Hawaii.

Follett, M. P. 1937. The process of control. In Papers on the science of administration, edited by L. Gulick and L. Urwick. New York: Columbia University.

Freud, S. 1922/1959. Group psychology and the analysis of the ego. Translated by J. Strachey. New York: Norton.

Giddens, A. 1979. Central problems in social theory. Berkeley: University of California.

Haldane, J. S. 1931. The philosophical basis of biology. London: Hodder and Stoughton.

Holland, J. 1992. Genetic algorithms. Scientific American July:66-72.

Holldobler, B., and E. O. Wilson. 1990. Ants. Cambridge, MA: Belknap.

Huizinga, J. 1950. Homo ludens. Boston: Beacon.

Katz, D., and R. Kahn. 1966. The social psychology of organization. New York: Wiley.

Kroeber, A. L. 1952. The nature of culture. Chicago: University of Chicago.

Langer, S. K. 1951. Philosophy in a new key. Cambridge, MA: Boston.

1962. Philosophical sketches. Baltimore, MD: Hopkins.

1967. Mind: An essay on human feeling. Baltimore, MD: Hopkins. 
Le Bon, G. 1903. The crowd. New York: Holt.

Levy-Bruhl, L. 1926/1985. How natives think. Princeton, NJ: Princeton.

. 1931. The solidarity of the individual with his group. In The making of man, edited by V. F. Calverton. New York: Modern Library.

Maclean, N. 1992. Young men and fire. Chicago: University of Chicago.

Metcalf, H. C., and L. Urwick, eds. 1942. Dynamic administration: The collected papers of Mary Follett. New York: Harper \& Brothers.

Morgan, G. 1986. Images of organization. Beverly Hills, CA: Sage.

Nielson, J. M. 1962. Agnosia, apraxia, aphasia. New York: Hafner.

Parsons, T., and E. A. Shils, eds. 1951. Toward a general theory of action. Cambridge, MA:Harvard.

Piaget, J. 1968. Six psychological studies. New York: Vintage.

Sandelands, L. E., and R. Drazin. 1989. On the language of organization theory. Organization Studies 10/4:457-478.

Sandelands, L. E., and R. E. Stablein. (1987). The concept of organization mind. In Research in the sociology of organizations, Vol. 5, edited by S. Bachrach and N. DiTomaso. Greenwich, CT: JAI.

Sandelands, L. E., and L. St. Clair. 1993. Toward an empirical concept of group. Journal for the Theory of Social Behaviour 23(4):423-458.

Searle, J. 1984. Minds, brains, and science. Cambridge, MA: Harvard.

Seitz, J. A., and H. Beilin. 1987. The development of comprehension of physiognomic metaphor in photographs. British Journal of Developmental Psychology 5:321-331.

Selznick, P. 1956. Leadership in administration. New York: Harper \& Row.

Sheehan, N. W., D. E. Papalia-Finlay, and F. H. Hooper. 1980. The nature of the life concept across the life-span. International Journal of Aging and Human Development 12:1-13.

Simmel, G. 1971. On individuality and social forms. Edited by D. N. Levine. Chicago: University of Chicago.

Sperry, R. 1985. Mind enfolds matter: Evolution and God (an exchange between Roger Sperry and Brian Josephson). In Nobel Prize conversations, edited by J. Eccles et al. San Francisco: Saybrook.

Stock, D., and H. A. Thelen. 1958. Emotional dynamics and group culture. New York: New York University for National Training Laboratories.

Thompson, D'Arcy. 1961. On growth and form. Cambridge: Cambridge University.

Thompson, J. D. 1967. Organizations in action. New York: McGraw-Hill.

Tielhard de Chardin, P. 1964. The future of man. New York: Harper \& Row.

Toennies, F. 1876/1957. Gemeinschaft and gesellschaft. Translated by C. P. Loomis. Lansing, MI: Michigan State University.

Weick, K. 1993. The collapse of sensemaking in organizations: The Mann Gulch disas ‘er. Administrative Science Quarterly 38(4):628-652.

Wheeler, W. M. 1939. Essays in philosophical biology. New York: Russell and Russell.

Whitehead, A. N. 1934. Nature and life. Chicago: University of Chicago.

Wierba, E., and D. Allison. 1994. The personal and social truths of improvisational theatre. Unpublished manuscript. Department of Psychology, University of Michigan.

Wilson, E. O. 1975. Sociobiology: The new synthesis. Cambridge, MA: Harvard.

Lloyd E. Sandelands is an associate professor of psychology and an associate professor of business administration at the University of Michigan. His interests center on whole properties of social life (social forms) and their analysis. 